\title{
Economic impact of longer battery life of cardiac resynchronization therapy defibrillators in Sweden
}

This article was published in the following Dove Press journal:

ClinicoEconomics and Outcomes Research

31 October 2016

Number of times this article has been viewed

\author{
Fredrik Gadler' \\ Yao Ding ${ }^{2}$ \\ Nathalie Verin ${ }^{3}$ \\ Martin Bergius ${ }^{4}$ \\ Jeffrey D Miller ${ }^{5}$ \\ Gregory M Lenhart ${ }^{5}$ \\ Mason W Russell ${ }^{5}$ \\ 'Department of Cardiology, \\ Karolinska University Hospital, \\ Stockholm, Sweden; ${ }^{2}$ Truven \\ Health Analytics, an IBM Company, \\ Bethesda, MD, USA; ${ }^{3}$ Boston Scientific \\ Corporation, Hemel Hempstead, \\ Hertfordshire, UK; ${ }^{4}$ Boston Scientific \\ Nordic AB, Helsingborg, Sweden; \\ ${ }^{5}$ Truven Health Analytics, an IBM \\ Company, Cambridge, MA, USA
}

Correspondence: Jeffrey D Miller Truven Health Analytics, an IBM Company, 75 Binney Street, Cambridge, MA 02142, USA

Tel +l 9787603886

Email jeffrey.d.miller@truvenhealth.com
Objective: The objective of this study was to quantify the impact that longer battery life of cardiac resynchronization therapy defibrillator (CRT-D) devices has on reducing the number of device replacements and associated costs of these replacements from a Swedish health care system perspective.

Methods: An economic model based on real-world published data was developed to estimate cost savings and avoided device replacements for CRT-Ds with longer battery life compared with devices with industry-standard battery life expectancy. Base-case comparisons were performed among CRT-Ds of three manufacturers - Boston Scientific Corporation, St. Jude Medical, and Medtronic - over a 6-year time horizon, as per the available clinical data. As a sensitivity analysis, we evaluated CRT-Ds as well as single-chamber implantable cardioverter defibrillator (ICD-VR) and dual-chamber implantable cardioverter defibrillator (ICD-DR) devices over a longer 10-year period. All costs were in 2015 Swedish Krona (SEK) discounted at 3\% per annum. Results: Base-case analysis results show that up to 603 replacements and up to SEK 60.4 million cumulative-associated costs could be avoided over 6 years by using devices with extended battery life. The pattern of savings over time suggests that savings are modest initially but increase rapidly beginning in the third year of follow-up with each year's cumulative savings two to three times the previous year. Evaluating CRT-D, ICD-VR, and ICD-DR devices together over a longer 10-year period, the sensitivity analysis showed 2,820 fewer replacement procedures and associated cost savings of SEK 249.3 million for all defibrillators with extended battery life. Conclusion: Extended battery life is likely to reduce device replacements and associated complications and costs, which may result in important cost savings and a more efficient use of health care resources as well as a better quality of life for heart failure patients in Sweden.

Keywords: cost analysis, economic model, cardiac resynchronization therapy defibrillator, implantable cardioverter defibrillator, battery life, device replacement, Sweden

\section{Introduction}

Cardiovascular diseases are the leading cause of death worldwide, representing $31 \%$ of all global deaths in 2012. ${ }^{1}$ A recent epidemiologic study estimated prevalence of heart failure (HF) in Sweden as 2.2\%, with incidence of 3.8/1,000 person-years and mortality of 3.1/1,000 person-years based on an administrative health data register consisting of 2.1 million Swedish inhabitants. ${ }^{2}$ The total aggregate cost for patients with HF in Sweden has been estimated in the range of SEK 5-6 billion. ${ }^{3}$

Implantable cardioverter defibrillator (ICD) devices, including implantable cardioverter defibrillators (ICDs) and cardiac resynchronization therapy defibrillators (CRT-Ds), have become increasingly important in HF management over the past several 
decades, and they have been shown to be cost-effective in improving HF patient outcomes, dramatically improving both patient quality and length of life. ${ }^{4-9}$ The use of implantable pacemakers is rooted in Swedish history, ever since the first implantation of an implantable cardiac pacemaker in a human being in 1958, done by the surgeon Åke Senning at Karolinska University Hospital in Stockholm, Sweden. ${ }^{10}$ Based on the data from the Swedish ICD and Pacemaker Registry, the implantation rate for CRT-Ds has increased $30 \%$ from 46 to 61 per million capita between 2012 and $2015 .{ }^{11}$ The progressive increase in CRT-D market share in Sweden reflects expanding indications from the European consensus guidelines. $^{4,12,13}$

CRT-D devices have a finite lifespan, and the majority of them need replacement between 4 and 9 years, principally not only because of battery depletion but also due to infection and other circumstances such as manufacturer recall, device or lead malfunction/failure, or change in patient's condition prompting the use of a different type of device. ${ }^{14-18}$ With more than one-half of Swedish patients younger than 70 years at the time of their first ICD or CRT-D implant, ${ }^{11}$ it is not unusual for patients to require several device replacements over their lifetime. Technological advances in device circuitry, programming, and battery capacity have contributed to significant extensions in the longevity of commercially available CRT-Ds. ${ }^{16}$ However, the increase in battery longevity is not consistent across all manufacturers, with some manufacturers showing superior battery longevity over others for a variety of complex reasons. ${ }^{16,19-23}$ In Sweden, procedures for replacement of ICDs and CRT-Ds, respectively, represent $32.0 \%$ and $37.7 \%$ of the total number of procedures in $2015 .{ }^{11}$ The total implant procedures reported for CRT-Ds is 981 (including 611 new implants and 370 replacements). ${ }^{11}$ Studies have shown that device-related complications (principally, post-implantation infections) are two to four times higher in patients undergoing device replacement compared with first-implant patients ${ }^{24,25}$ and such complications are associated with a significant increase in patient morbidity and mortality. ${ }^{26,27}$ Device replacement is an expensive procedure, comprising the cost of the new device, the cost of performing the surgery and managing the patient peri-operatively with clinic visits and medication, and dealing with the complications when they occur. ${ }^{16,20,24}$ Minimizing the frequency of device replacement by extending battery life not only can improve clinical outcomes but also may substantially reduce health care resource utilization and associated costs in HF patients - desirable for both patients and the health care system as a whole. A recent economic study conducted from a general European hospital perspective reported a total potential saving of 29-34\% over a 15 -year period by extending device longevity from 4-5 years to 7-9 years. ${ }^{25}$ Therefore, device longevity and real-world battery life are crucial considerations when selecting a CRT-D device for patients - for the welfare of not only the patients themselves but also their health care payers. ${ }^{15,22}$

The purpose of this study was to develop an economic model from the Swedish health care perspective to quantify the impact that longer CRT-D device battery life has on reducing the number of device replacements and the associated costs of these replacements. Our hypothesis was that longer battery life in CRT-D devices is associated with a reduction in the number of avoidable device replacements and will save health care costs in terms of devices, procedures, complications and long-term follow-up costs among HF patients implanted with CRT-Ds in Sweden.

\section{Methods \\ Model structure overview}

We developed an economic model to estimate the potential cost savings and avoided device replacements for CRT-Ds with longer battery life compared to CRT-D devices with industry-standard battery life expectancy. Data on CRT-D battery survival were obtained from a previously published report by Landolina et al. ${ }^{22}$ Data on all patients who had received a CRT-D system between 2008 and 2010 according to international recommendations were prospectively collected in the hospital databases of nine Italian implanting centers. The comparison of longevity among recentgeneration CRT-Ds from different manufacturers (e.g., Boston Scientific Corporation [BSC], St. Jude Medical [SJM] and Medtronic [MDT]) was performed only for subgroups with at least 100 devices in the analysis. Recentgeneration devices were identified as the most recent device families released onto the market, for the most part after $2007 .{ }^{22}$ The results from the study by Landolina et $\mathrm{al}^{22}$ showed that recent-generation BSC CRT-D devices have substantially longer battery life than CRT-D devices from the other two manufacturers, SJM and MDT. At 6 years, $88 \%$ of BSC CRT-D batteries were still in service compared to only $41 \%$ and $32 \%$ of SJM and MDT CRT-D batteries, respectively (Table 1 ).

As a sensitivity analysis, we looked at the broader spectrum of defibrillator technologies available in Sweden. We evaluated CRT-Ds as well as single-chamber implantable cardioverter defibrillator (ICD-VR) and dual-chamber implantable cardioverter defibrillator (ICD-DR) devices using battery life projections' data over a longer 10 -year period ${ }^{28,29}$ and compared two 
Table I Key input parameters in the base-case analysis model

\begin{tabular}{|c|c|c|c|}
\hline $\begin{array}{l}\text { Parameters for CRT-D } \\
\text { device analyses }\end{array}$ & BSC & SJM & MDT \\
\hline $\begin{array}{l}\text { Annual number of first } \\
\text { CRT-D implantation } \\
\text { procedures in Sweden" }\end{array}$ & 611 & 611 & 611 \\
\hline Device system price ${ }^{*, a}$ & SEK 4I,65I & SEK 44,606 & SEK 50,556 \\
\hline Device replacement price ${ }^{*, b}$ & SEK $36,65 I$ & SEK 39,256 & SEK 45,206 \\
\hline Procedure unit $\operatorname{cost}^{32}$ & SEK 59,613 & SEK 59,613 & SEK 59,613 \\
\hline Incidence of complication & & & \\
\hline Infection - first implant ${ }^{25}$ & $1 \%$ & $1 \%$ & $1 \%$ \\
\hline Infection - replacement ${ }^{25}$ & $2 \%$ & $2 \%$ & $2 \%$ \\
\hline $\begin{array}{l}\text { Complication } \operatorname{cost}^{\mathrm{c}}-\text { first } \\
\text { implant }\end{array}$ & SEK 4,986 & SEK 4,986 & SEK 4,986 \\
\hline $\begin{array}{l}\text { Complication } \operatorname{cost}^{\mathrm{c}}- \\
\text { replacement }^{5,33}\end{array}$ & SEK 8,577 & SEK 8,577 & SEK 8,577 \\
\hline Follow-up cost per patient $\mathrm{t}^{25,32, \mathrm{~d}}$ & $\begin{array}{l}2015 \text { SEK } \\
2,926\end{array}$ & $\begin{array}{l}2015 \text { SEK } \\
2,926\end{array}$ & $\begin{array}{l}2015 \text { SEK } \\
2,926\end{array}$ \\
\hline $\begin{array}{l}\text { Event-free battery survival } \\
\text { (ie, percentage of devices with } \\
\text { functional batteries and not } \\
\text { requiring replacement) }\end{array}$ & & & \\
\hline Year I & 100.000 & 100.000 & 100.000 \\
\hline Year 2 & 100.000 & 100.000 & 99.727 \\
\hline Year 3 & 99.180 & 98.361 & 94.812 \\
\hline Year 4 & 97.246 & 90.687 & 77.596 \\
\hline Year 5 & 88.048 & 75.410 & 51.639 \\
\hline Year 6 & 87.978 & 40.816 & 31.694 \\
\hline
\end{tabular}

Notes: *Documents and data obtained by request of the authors to 14 individual county councils/regions across Sweden (201I-2015) for Pacemaker Tenders Submissions in Sweden. a Device system price includes price of box and leads/ accessories for initial implant. 'Device replacement price includes price for box only. 'Complication cost includes cost of infections (e.g., costs of lead extraction, re-implants, and additional hospitalizations such as cardiac hospital stay and intensive cardiac unit care) and cost associated with lead malfunction/dislodgement (e.g. costs of lead replacement procedures and additional or prolonged hospitalizations). dFollow-up cost was the unit cost for a cardiology follow-up outpatient visit (SEK I,463) times the annual frequency of follow-up visits per patient $(2)$.

Abbreviations: BSC, Boston Scientific Corporation; CRT-D, cardiac resynchronization therapy defibrillator; MDT, Medtronic; SEK, Swedish krona; SJM, St. Jude Medical.

scenarios: current scenario using 2015 market share of devices in Sweden ${ }^{11}$ (Table 2) and alternative scenario modeling a $100 \%$ market share of devices with extended battery longevity.

All analyses in this study were conducted from a Swedish health care system perspective. The software platform on which the model was programmed was Microsoft Excel 2013 (Microsoft Corporation, Redmond, WA, USA). The study was exempt from institutional review board review, as it relied only on publicly available sources and did not involve human participant research.

\section{Base-case analysis (using published CRT-D battery survival data over a 6-year time horizon) Data sources}

The point estimates for input parameters (e.g., probabilities and costs) were derived from published literature and recent
Table 2 Selected input parameters in the sensitivity analysis

\begin{tabular}{|c|c|c|c|}
\hline Variable & ICD-VR & ICD-DR & CRT-D \\
\hline $\begin{array}{l}\text { Annual number of implants } \\
\text { (including new implants and } \\
\text { replacements) in Sweden" }\end{array}$ & 360 & 609 & 611 \\
\hline $\begin{array}{l}\text { Current market share for } \\
\text { BSC's extended longevity } \\
\text { devices (current scenario)" }\end{array}$ & $9 \%$ & $8 \%$ & $9 \%$ \\
\hline $\begin{array}{l}\text { Revised market share for } \\
\text { BSC's extended longevity } \\
\text { devices (revised scenario; } \\
\text { expert opinion) }\end{array}$ & $100 \%$ & $100 \%$ & $100 \%$ \\
\hline $\begin{array}{l}\text { System price of BSC's } \\
\text { extended longevity devices* }\end{array}$ & SEK 36,010 & SEK 38,263 & SEK 4I,65I \\
\hline $\begin{array}{l}\text { Replacement price }{ }^{\mathrm{b}} \text { of BSC's } \\
\text { extended longevity devices* }\end{array}$ & SEK 3I,0I0 & SEK 33,263 & SEK 36,65I \\
\hline $\begin{array}{l}\text { Market average }{ }^{c} \text { device } \\
\text { system price* }\end{array}$ & SEK 42,032 & SEK 43,418 & SEK 49,938 \\
\hline $\begin{array}{l}\text { Market average }{ }^{c} \text { device } \\
\text { replacement price* }\end{array}$ & SEK 36,682 & SEK 38,068 & SEK 44,588 \\
\hline $\begin{array}{l}\text { Battery longevity for BSC's } \\
\text { extended longevity devices } \\
28\end{array}$ & 13.1 years & II.5 years & 9.6 years \\
\hline $\begin{array}{l}\text { Market average }{ }^{c} \text { battery } \\
\text { longevity }{ }^{29}\end{array}$ & 7.1 years & 7.I years & 5.8 years \\
\hline
\end{tabular}

Notes: *Documents and data obtained by request of the authors to 14 individual county councils/regions across Sweden (201 I-2015) for Pacemaker Tenders Submissions in Sweden. ${ }^{2}$ System price includes device price of box and leads/accessories for initial

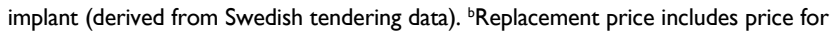
box only (derived from Swedish tendering data). 'Market average was the mean value of device price or longevity of competitor manufacturers, including SJM, MDT, Sorin Group, and Biotronik (derived from Swedish tendering data or NICE report).

Abbreviations: BSC, Boston Scientific Corporation; CRT-D: Cardiac resynchronization therapy defibrillator; ICD-DR: Dual-chamber implantable cardioverter defibrillator; ICD-VR: Single-chamber implantable cardioverter defibrillator; SEK: Swedish krona; NICE, National Institute for Health and Care Excellence; SJM, St. Jude Medical.

(2014 and 2015) data from the Swedish ICD and Pacemaker Registry, supplemented by historical Swedish public tendering data between 2011 and 2015.

\section{Model parameters}

The selected input parameters in the base case are listed in Table 1, and all calculations were based on CRT-D devicespecific data in Sweden. We conservatively assumed that the annual CRT-D implantation capacity is 611 with a yearly growth rate of $8 \%$ in Sweden based on the 2015 Swedish ICD and Pacemaker Registry's statistical report (611 was reported as the annual new implant number of CRT-D devices in 2015 and $8 \%$ was estimated as an average growth rate between 2011 and 2015). ${ }^{11}$ Our base-case modeling analysis estimated the expenditure associated with CRT-D device implantation over a 6-year time horizon in three scenarios (i.e., 100\% BSC, 100\% SJM, and $100 \%$ MDT) with incremental comparisons against BSC.

Year-by-year patient survival rates were based on published survival curves of a population of consecutive patients implanted with CRT-D devices. ${ }^{30}$ In the base-case 


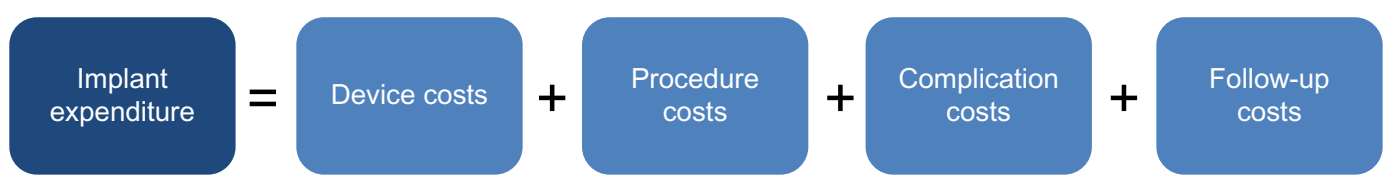

Figure I Cost calculation in the economic model.

analysis, yearly battery survival rates of CRT-D devices for each manufacturer were based on a real-world analysis of nine Italian hospitals over 6 years, as presented in Figure 3 by Landolina et al. ${ }^{22}$ These event-free battery survival data were derived from the graph using Engauge Digitizer 5.1 (SourceForce.net, http://markummitchell.github.io/engaugedigitizer/), which is an open-source digitizing software for converting an image file of graphs into numbers (Table 1). Yearly battery failure rates (i.e., $F_{n}$ with $n$ ranging from 0 to 6 years) by the manufacturer were calculated by one minus their corresponding survival rates. The calculations for probabilities of first, second, and third replacements of CRT-D devices are presented in the Supplementary material. In this study, we assumed that all devices are replaced at the end of their serviceable life if the patient is still alive. Therefore, our model captured all initial implantations in the 6-year basecase study period and any replacements for these patients (if required) during the same time period.

Cost parameters in the model included not only the cost of device implants attributable to initial implantation but also the cost of replacement and associated complications and follow-up. The base-case analysis estimated year-byyear and cumulative expenditure of device replacements in patients implanted with CRT-Ds over a 6-year time horizon in Sweden. The cost components for device replacements included the following: 1) device costs (i.e., costs of the device without the leads; 2) procedure costs (i.e., surgical procedure and hospitalization costs); 3) complication costs (i.e., costs of managing implantation complications); and 4) follow-up costs (i.e., costs of follow-up medical visits specific to the replacement implantation; Figure 1). All costs were discounted at a 3\% annual rate per Swedish Pharmacoeconomics guidelines $^{31}$ and were reported in 2015 Swedish krona (SEK).

CRT-D device costs were derived from our synthesis and analysis of 2011-2015 Swedish public tenders' data, which include both defibrillator system price (i.e., price of box plus leads/accessories for initial implant) and replacement price (i.e., price for box only) by manufacturer (Table 1). Surgical procedure costs for initial CRT-D implant or device replacement were derived from a published cost-of-illness study. ${ }^{32}$ Complication-associated costs include costs of infections (e.g., costs of lead extraction, re-implants, and additional hospitalizations such as cardiac hospital stay and intensive cardiac unit care) and expenditures associated with lead malfunction/dislodgement (e.g., costs of lead replacement procedures and additional or prolonged hospitalizations). Additional hospitalization days, treatment costs, and frequency of complications were calculated based on information from the published literature. ${ }^{5,25,33}$ Follow-up costs were calculated by multiplying the unit cost for a cardiology follow-up outpatient visit ${ }^{32}$ by the annual frequency of followup visits, as reported in Boriani et al. ${ }^{25}$

\section{Sensitivity analysis (using battery longevity projections data over 10 years)}

We performed sensitivity analysis to evaluate changes in potential cost savings and avoided device replacements when extending the follow-up period from 6 to 10 years after the initial implant and including a broader spectrum of defibrillator technologies other than CRT-Ds (i.e., ICD-VR and ICD-DR devices). The analysis compared the following two scenarios: 1) current scenario - assumes that the proportion of devices from different manufacturers (including BSC, SJM, MDT, Sorin Group [now LivaNova], and Biotronik) is the same as the current usage in Sweden, ${ }^{11}$ and 2) alternative scenario - assumes that patients use a higher proportion (e.g., $100 \%$ ) of extended battery longevity devices for all defibrillator implants. Each scenario considered the same number of patients undergoing an initial defibrillator implantation every year and used battery longevity projections data derived from the BSC LATITUDE® Patient Management System for BSC devices ${ }^{28}$ and the UK National Institute for Health and Care Excellence for other manufacturers. ${ }^{29}$ The key input parameters in the sensitivity analysis are shown in Table 2, with cost components reported in 2015 SEK and discounted at a 3\% annual rate, and patient survival rates derived from the same data sources as in the base-case analysis but expanded to include device-specific estimates for ICD-VR and ICD-DR. . $, 15,25,30,32,33^{2}$

\section{Results \\ Base-case analysis results}

The primary outcome measures are: 1) the reduction in the number of replacement procedures due to extended CRT-D 
battery life, and 2) the cost savings associated with the reduction of replacement procedures, in the Swedish health care system. Direct comparisons were made for CRT-D devices manufactured by BSC (shown to have the highest probability of device survival at 6 years) versus devices manufactured by SJM and MDT. As demonstrated in Table 3, up to 603 replacement procedures and up to SEK 60.4 million cumulative-associated costs could be avoided over a 6-year time period by using BSC CRT-D devices with longer battery life. The pattern of savings over time suggests that savings are modest initially but they increase rapidly beginning in the third year of follow-up with each year's cumulative savings two to three times the previous year. Figures 2 and 3, respectively, demonstrate the year-by-year expenditure and the cumulative expenditure trend for CRT-D

Table 3 Base-case results for CRT-D devices

\begin{tabular}{ll}
\hline Outcome measure & \\
\hline Avoided replacement procedures over 6 years & Reduction number \\
BSC vs SJM & 323 \\
BSC vs MDT & 603 \\
Cost savings for device replacements ${ }^{\mathrm{a}}$ & Over 6 years \\
BSC vs SJM & SEK 30.2 million \\
BSC vs MDT & SEK 60.4 million
\end{tabular}

Notes: All costs reported in 2015 SEK discounted at $3 \%$ per annum. ${ }^{\text {a Costs of }}$ CRT-D device replacements include cost of replacement devices and associated procedures, cost of managing complications related to replacement procedures, and cost of follow-up visits specific to the replacements.

Abbreviations: BSC, Boston Scientific Corporation; CRT-D, cardiac resynchronization therapy defibrillator; MDT, Medtronic; SEK, Swedish krona; SJM, St. Jude Medical. device replacements by the manufactures over a 6-year time horizon in Sweden.

\section{Sensitivity analysis results}

We performed a sensitivity analysis to estimate the costs associated with switching from the current market share of ICD-VR, ICD-DR, and CRT-D devices in Sweden to a larger market share of devices with extended battery life over a 10-year time horizon. Our results suggest that up to 2,820 replacement procedures could be avoided and there is an associated cost savings of SEK 249.3 million for all the three types of defibrillators (Figure 4).

\section{Discussion}

CRT-D and ICD replacement procedures due to battery depletion carry considerable risk of complications and discomfort for the patients. Device replacement is also costly and resource demanding for health care systems in a time of limited resources. Therefore, battery longevity is an extremely important factor from both a clinical and economic standpoint, as shown by the results of the analyses we present here. Using the economic model we developed to assess the economic benefits of longer device battery life, we found that a longer battery life in CRT-D devices is associated with a reduction in the number of avoidable device replacements and leads to substantial cost savings for the Swedish health care system, ranging from SEK 30 million to SEK 60 million for BSC vs. SJM and BSC vs. MDT, respectively, over the 6-year time horizon.

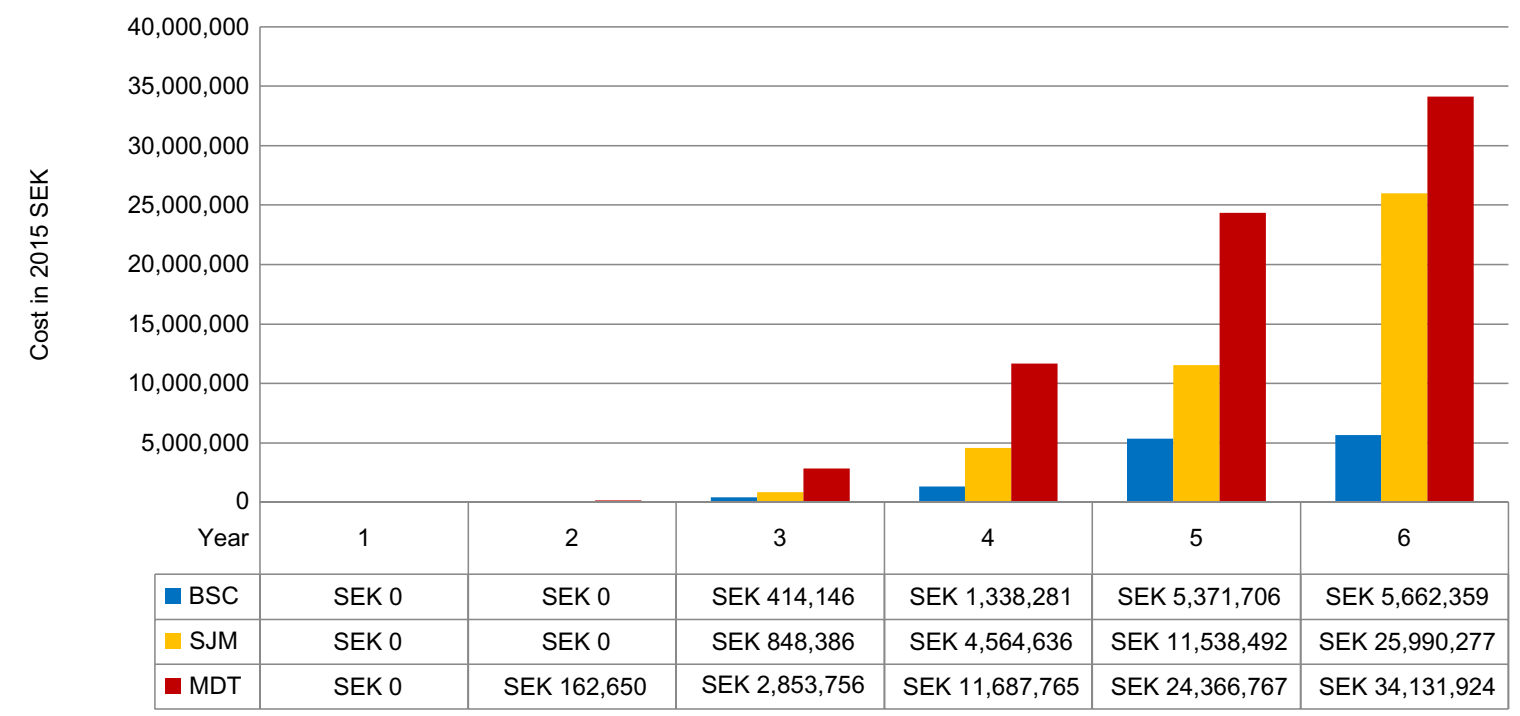

Figure 2 Yearly cost of CRT-D device replacements ${ }^{\mathrm{a}}$ in the base-case analysis.

Notes: All costs reported in 2015 SEK discounted at 3\% per annum. a Costs of CRT-D device replacements include cost of replacement devices and associated procedures, cost of managing complications related to replacement procedures, and cost of follow-up visits specific to the replacements.

Abbreviations: BSC, Boston Scientific Corporation; CRT-D, cardiac resynchronization therapy defibrillator; MDT, Medtronic; SEK, Swedish krona; SJM, St. Jude Medical. 


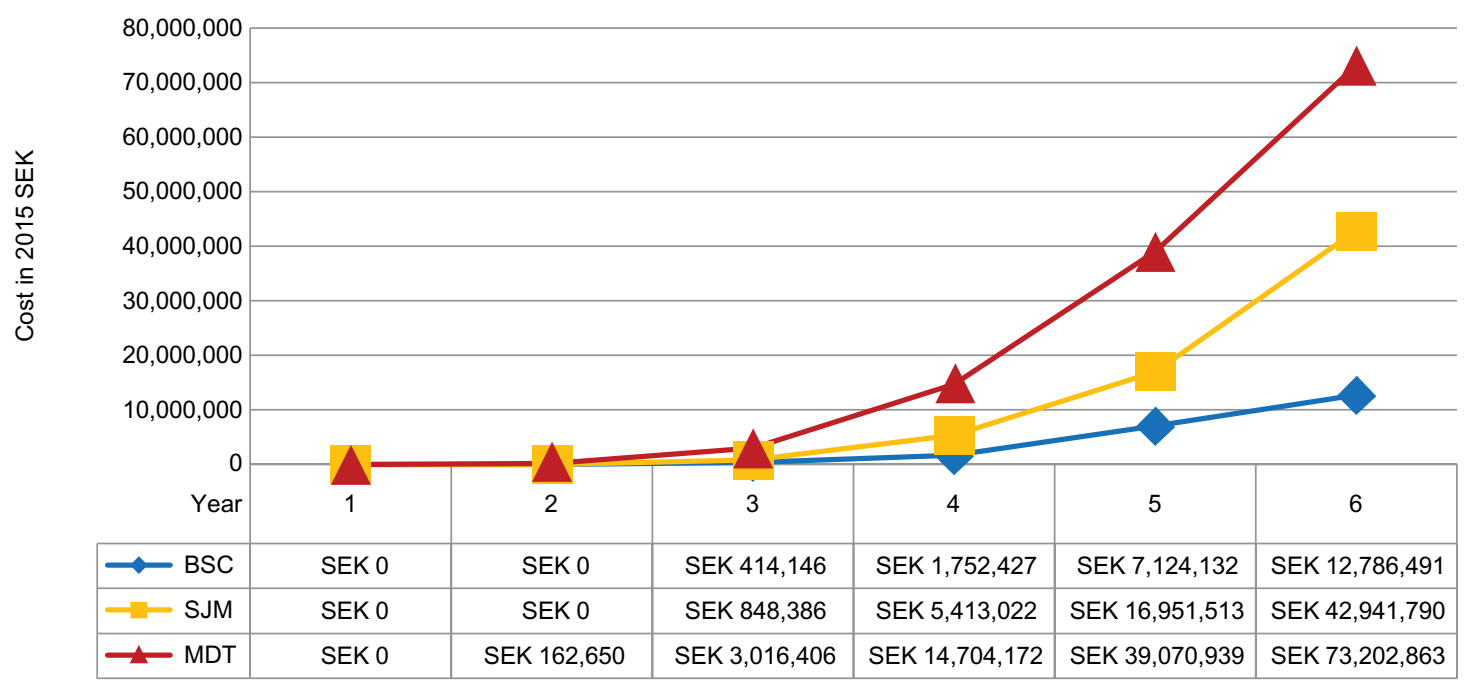

Figure 3 Cumulative cost of CRT-D device replacements ${ }^{\mathrm{a}}$ over 6 years in the base-case analysis

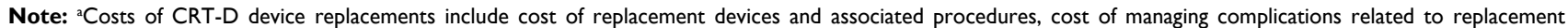
procedures, and cost of follow-up visits specific to the replacements.

Abbreviations: BSC, Boston Scientific Corporation; CRT-D, cardiac resynchronization therapy defibrillator; MDT, Medtronic; SEK, Swedish krona; SJM, St. Jude Medical.

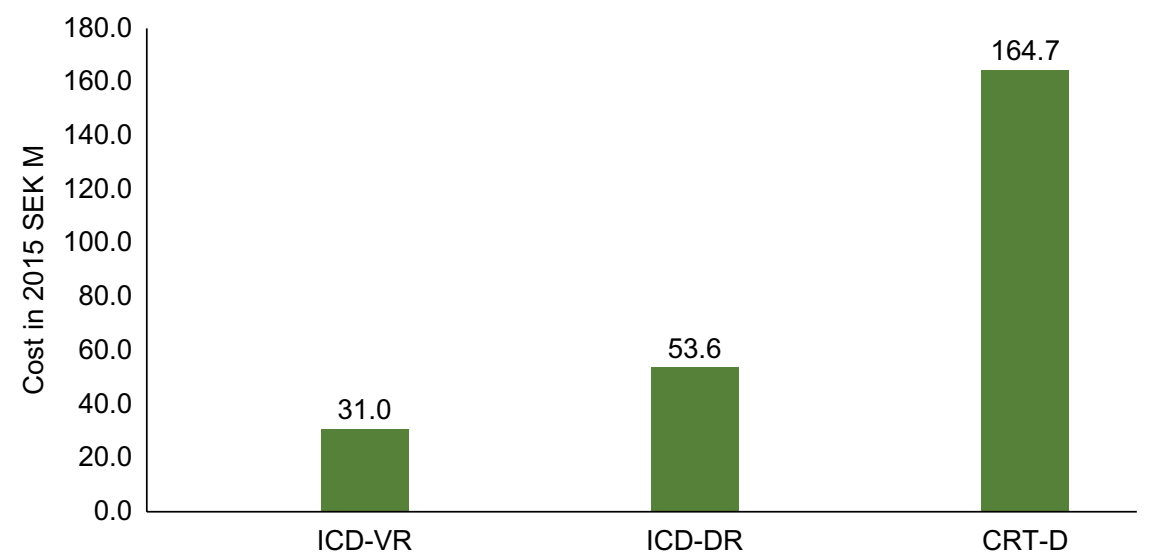

Figure 4 Sensitivity analysis results: replacement cost savings over 10 years.

Note: This figure shows the replacement cost savings by device type over 10 years with costs reported in 2015 SEK M.

Abbreviations: CRT-D, cardiac resynchronization therapy defibrillator; ICD-DR: dual-chamber implantable cardioverter defibrillator; ICD-VR: single-chamber implantable cardioverter defibrillator; SEK M, Swedish krona in million.

This is the first study to evaluate the economic impact of improved CRT-D and ICD battery longevity in Sweden. There are several other studies on this topic that have been published in recent years but we have collected a complete national data set for Sweden for the first time. Our study shows some alignment with the 2010 study by Ramachandra, ${ }^{17}$ reporting that longer lasting ICDs reduce the need for replacements. Using a retrospective review of Veterans Affairs records, with a study cohort of 164 patients with 301 ICD implants, Ramachandra found that if all ICDs had lasted 5, 7, or 9 years, then $26 \%, 58 \%$, and $84 \%$ of patients would not have needed an ICD replacement. Also, 17, 37, and 53 ICD replacements, respectively, would have been avoided, saving US\$314,500US\$980,500 (US\$2,005) over 15 years. ${ }^{17}$
In a model-based cost analysis similar to ours, Boriani et $\mathrm{a}^{25}$ estimated the cost impact of extending the longevity of ICD and CRT-D devices in different clinical scenarios. The authors showed that extending the longevity of the device has an important impact in reducing long-term costs of device therapy, with substantial savings in favor of the devices with extended longevity. Over a 15 -year time horizon, total, yearly, and per diem savings per patient from extending ICD longevity to 9 years were $€ 8,000-€ 11,000$, $€ 500-€ 700$, and $€ 1.40-€ 1.99$, while total, yearly, and per diem savings from extending CRT-D longevity to 7 years were $€ 11,000-€ 14,000, € 700-€ 900$, and $€ 2.00-€ 2.49$. Avoidance of a device replacement amounted to $46.6-62.5 \%$ of the savings. 
In another study, Biffi et $\mathrm{al}^{34}$ determined that the true cost of ICD treatment is strictly dependent on device longevity, whereas device upfront cost is unreliable. Longer lasting devices had a significantly lower daily cost: $€ 6.90$ vs. $€ 12.60-€ 13.40$ for ICD-DR devices (depending on the manufacturer). The authors suggest that advantages of longevity should be valued in the technology purchasing process and could set the basis for an outcome-based reimbursement system.

In Sweden, county- and municipal-level authorities play a large role in administering health care services as well as setting local health care budgets and overseeing procurement of medical devices and supplies, such as CRT-D. One of the important strengths of this study comes from our use of realworld ICD-VR, ICD-DR, and CRT-D devices' pricing data derived from 5 years (2011-2015) of Swedish public tender submissions. We obtained these tenders' data directly from 14 individual county councils representing the vast majority of Sweden. The data available in the tender documents are very rich in details (including battery longevity claims) and reflect the information available to contracting authorities to balance costs and quality indicators in their decisions about how to use public funds to finance ICD and CRT devices in the most cost-effective way. The results of our analyses showed that the market average system prices (2015 SEK) for CRT-D devices ranged from SEK 41,651, SEK 44,606, and SEK 50,556 for BSC, SJM, and MDT devices, respectively (Table 1). System replacement prices were $\sim 11.5 \%$ (SEK 5,233) less on average. We also used results from our analysis of tender's data in the model sensitivity analyses, where the market average system prices for extended longevity devices ranged from SEK 42,032, SEK 43,418, and SEK 49,938 for ICD-VR, ICD-DR, and CRT-D, respectively (Table 2). Replacement prices were $\sim 12 \%$ (SEK 5,350) less on average. In light of the fact that health decision-makers involved with coverage and payment policies are increasingly seeking real-world information on which to base their decisions, we believe using these Swedish tenders' data in our model provides an additional level of credibility to the study findings as it reflects current practice and economics on a national basis.

"Real world" ICD and CRT-D battery life can differ from those stated in the manufacturers' manuals and labeling, which are based on hypothetical statistical characterizations or well-controlled laboratory testing conditions, all of which are dictated by very specific settings of the device programming that may not well reflect actual clinical use. ${ }^{16,18,22,35}$ All manufacturers have a "warranty" program in place to guarantee the devices that might fail sooner than expected. However, the terms of a device's warranty may differ substantially from its practical "longevity", and in many cases, local clinics are not aware of current warranties and fail to use them. Regardless of whether warranties are used, patients are still subject to the risk of avoidable replacement procedures. One of the strengths of our model comes from the use of real-world CRT-D battery life data. ${ }^{22}$ Analyzing the data on 1,726 CRT-D systems implanted in 2008-2010 in nine Italian centers, Landolina et $\mathrm{a}^{22}$ found that 5 years after a successful CRT-D implantation procedure, $46 \%$ of devices were replaced due to battery depletion. Notably, the time to device replacement for battery depletion differed considerably among currently available CRT-D systems from different manufacturers. We disaggregated these data into annual cut points (Table 1) and found the rate of batteries still in service at 6 years was $88 \%$ for BSC, $41 \%$ for SJM, and $32 \%$ for MDT.

Another strength of our model is the use of real-world ICD and CRT-D implantation data statistics from the Swedish ICD and Pacemaker Registry, ${ }^{11}$ a national, longitudinal database in Sweden that collects prospective data on all pacemakers and ICD/CRT implanting activities in Sweden, thereby providing a real-time picture of their use across Sweden.

A potential limitation of our study is that no single source of data was available for informing all the parameters in the economic model. Instead, we had to rely on a mix of sources, some of which required assumptions or custom analyses to adapt them to the data needs of the model. For example, the battery longevity data from Landolina et $\mathrm{al}^{22}$ were from the Italian health care setting, whereas the most ideal data for our Swedish perspective model would have been obtained from pacemaker implantation centers in Sweden. The data from Landolina et $\mathrm{a}^{22}$ were limited to CRT-D devices for only three manufacturers. Ideally, we would have had access to comparable data for ICD-VR and ICD-DR devices as well. Instead, we included ICD-VR and ICD-DR devices for sensitivity analysis, but based on an alternative data source.

\section{Conclusion}

Unquestionably, CRT-D devices have made a positive impact on thousands of patients in Sweden by slowing their HF progression and giving them better health and quality of life. Technological advances in battery technology allow physicians to offer patients longer lasting devices that minimize complications and improve quality of life, while payers can more effectively manage health care costs. Increasing the use of longer-lasting devices can provide an opportunity to generate savings that can 
be reinvested in other parts of the health care system. Devices with longer battery life have an important implication on the cost-effectiveness of treatments for HF patients, particularly as the technologies continue to evolve and improve.

\section{Acknowledgment}

Funding for this study was provided by Boston Scientific Nordic AB (Helsingborg, Sweden).

\section{Disclosure}

Two of the authors, NV and MB, are employed by BSC and Boston Scientific Nordic AB, respectively, which manufacturer and market ICD and CRT-D devices discussed in this article. The authors have no other relevant affiliations or financial involvement with any organization or entity with a financial interest in or financial conflict with the subject matter or materials discussed in the manuscript apart from those disclosed. The authors report no other conflicts of interest in this work.

\section{References}

1. WHO [webpage on the Internet]. World Health Organization - Fact Sheet 2015 for Cardiovascular Diseases (CVDs). Geneva: World Health Organization; 2015. Available from: http://www.who.int/mediacentre/ factsheets/fs317/en/. Accessed August 5, 2016.

2. Zarrinkoub R, Wettermark B, Wandell P, et al. The epidemiology of heart failure, based on data for 2.1 million inhabitants in Sweden. Eur J Heart Fail. 2013;15(9):995-1002.

3. Agvall B, Borgquist L, Foldevi M, Dahlstrom U. Cost of heart failure in Swedish primary healthcare. Scand J Prim Health Care. 2005;23(4):227-232.

4. Cleland JG, Daubert JC, Erdmann E, et al. The effect of cardiac resynchronization on morbidity and mortality in heart failure. NEngl J Med. 2005;352(15):1539-1549.

5. Blomstrom P, Ekman M, Lundqvist CB, et al. Cost effectiveness of cardiac resynchronization therapy in the Nordic region: an analysis based on the CARE-HF trial. Eur J Heart Fail. 2008;10(9):869-877.

6. McAlister FA, Ezekowitz J, Hooton N, et al. Cardiac resynchronization therapy for patients with left ventricular systolic dysfunction: a systematic review. JAMA. 2007;297(22):2502-2514.

7. European Society of C, European Heart Rhythm A. Brignole M, et al. ESC guidelines on cardiac pacing and cardiac resynchronization therapy: the task force on cardiac pacing and resynchronization therapy of the European Society of Cardiology (ESC). Developed in collaboration with the European Heart Rhythm Association (EHRA). Europace. 2013;15(8):1070-1118.

8. Calvert MJ, Freemantle N, Yao G, et al. Cost-effectiveness of cardiac resynchronization therapy: results from the CARE-HF trial. Eur Heart J. 2005;26(24):2681-2688.

9. Gialama F, Prezerakos P, Maniadakis N. The cost effectiveness of implantable cardioverter defibrillators: a systematic review of economic evaluations. Appl Health Econ Health Policy. 2014;12(1):41-49.

10. Elmqvist R, Senning A. Implantable pacemaker for the heart. In: Smyth $\mathrm{CN}$, editor. Medical electronics: Proceedings of the Second International Conference on Medical Electronics, Paris, June 24-27, 1959. London: Iliffe; 1960:253-254.

11. Swedish ICD and Pacemaker Registry [webpage on the Internet]. Swedish ICD \& Pacemaker Registry. Annual Statistical Report. 2015. Available from: https://www.pacemakerregistret.se/icdpmr/docbankView. do?id=-er3_cQ----KFLbTVD0FrN7A. Accessed August 5, 2016.
12. Linde C, Abraham WT, Gold MR, et al. Randomized trial of cardiac resynchronization in mildly symptomatic heart failure patients and in asymptomatic patients with left ventricular dysfunction and previous heart failure symptoms. J Am Coll Cardiol. 2008;52(23):1834-1843.

13. Swedberg K, Cleland J, Dargie H, et al. Guidelines for the diagnosis and treatment of chronic heart failure: executive summary (update 2005): The Task Force for the Diagnosis and Treatment of Chronic Heart Failure of the European Society of Cardiology. Eur Heart J. 2005;26(11):1115-1140.

14. Gepner K, Przybylski A, Maciag A, et al. Causes of redo procedures in patients with an implantable cardioverter-defibrillator - long-term follow-up results. Kardiol Pol. 2007;65(8):893-898. discussion 899.

15. Hauser RG. The growing mismatch between patient longevity and the service life of implantable cardioverter-defibrillators. J Am Coll Cardiol. 2005;45(12):2022-2025.

16. Horlbeck FW, Mellert F, Kreuz J, Nickenig G, Schwab JO. Real-world data on the lifespan of implantable cardioverter-defibrillators depending on manufacturers and the amount of ventricular pacing. J Cardiovasc Electrophysiol. 2012;23(12):1336-1342.

17. Ramachandra I. Impact of ICD battery longevity on need for device replacements-insights from a veterans affairs database. Pacing Clin Electrophysiol. 2010;33(3):314-319.

18. Thijssen J, Borleffs CJ, van Rees JB, et al. Implantable cardioverterdefibrillator longevity under clinical circumstances: an analysis according to device type, generation, and manufacturer. Heart Rhythm. 2012;9(4):513-519.

19. Alam MB, Munir MB, Rattan R, Adelstein E, Jain S, Saba S. Battery longevity from cardiac resynchronization therapy defibrillators: differences between manufacturers and discrepancies with published product performance reports. Europace. 2016. Epub 2016 Mar 22.

20. Alam MB, Munir MB, Rattan R, et al. Battery longevity in cardiac resynchronization therapy implantable cardioverter defibrillators. Europace. 2014;16(2):246-251.

21. Ellis CR, Dickerman DI, Orton JM, et al. Ampere hour as a predictor of cardiac resynchronization defibrillator pulse generator battery longevity: a multicenter study. Pacing Clin Electrophysiol. 2016;39(7):658-668.

22. Landolina M, Curnis A, Morani G, et al. Longevity of implantable cardioverter-defibrillators for cardiac resynchronization therapy in current clinical practice: an analysis according to influencing factors, device generation, and manufacturer. Europace. 2015;17(8):1251-1258.

23. von Gunten S, Schaer BA, Yap SC, et al. Longevity of implantable cardioverter defibrillators: a comparison among manufacturers and over time. Europace. 2016;18(5):710-717.

24. Poole JE, Gleva MJ, Mela T, et al. Complication rates associated with pacemaker or implantable cardioverter-defibrillator generator replacements and upgrade procedures: results from the REPLACE registry. Circulation. 2010;122(16):1553-1561.

25. Boriani G, Braunschweig F, Deharo JC, Leyva F, Lubinski A, Lazzaro C. Impact of extending device longevity on the long-term costs of implantable cardioverter-defibrillator therapy: a modelling study with a 15-year time horizon. Europace. 2013;15(10):1453-1462.

26. Sohail MR, Henrikson CA, Braid-Forbes MJ, Forbes KF, Lerner DJ. Mortality and cost associated with cardiovascular implantable electronic device infections. Arch Intern Med. 2011;171(20):1821-1828.

27. Uslan DZ, Gleva MJ, Warren DK, et al. Cardiovascular implantable electronic device replacement infections and prevention: results from the REPLACE Registry. Pacing Clin Electrophysiol. 2012;35(1): 81-87.

28. Boston Scientific Corporation (BSC). LATITUDE® Patient Management System Data as of 01/01/2014 for BSC Longevity Estimates. Marlborough, MA: Boston Scientific Corporation (BSC); 2014.

29. NICE [webpage on the Internet]. National Institute for Health \& Care Excellence (NICE) Report for Final Appraisal Determination: Implantable Cardioverter Defibrillators and Cardiac Resynchronisation Therapy for Arrhythmias and Heart Failure. 2014. Available from: https:/www.nice.org.uk/guidance/ta314/documents/arrythmias-icdsheart-failure-cardiac-resynchronisation-fad-document2. Accessed August 5, 2016. 
30. Yao G, Freemantle N, Calvert MJ, Bryan S, Daubert JC, Cleland JG. The long-term cost-effectiveness of cardiac resynchronization therapy with or without an implantable cardioverter-defibrillator. Eur Heart J. 2007;28(1):42-51.

31. Tandvårds- och läkemedelsförmånsverket (TLV) [The Dental and Pharmaceutical Benefits Agency]. General Guidelines for Economic Evaluations from the Pharmaceutical Benefits Board. LFNAR 2003:2. Available from: http://www.tlv.se/Upload/English/Guidelines-foreconomic-evaluations-LFNAR-2003-2.pdf. Accessed August 5, 2016.

32. Jonsson L, Eliasson A, Kindblom J, Almgren O, Edvardsson N. Cost of illness and drivers of cost in atrial fibrillation in Sweden and Germany. Appl Health Econ Health Policy. 2010;8(5):317-325.
33. Ericson L, Bergfeldt L, Bjorholt I. Atrial fibrillation: the cost of illness in Sweden. Eur J Health Econ. 2011;12(5):479-487.

34. Biffi M, Ziacchi M, Bertini M, et al. How to truly value implantable cardioverter-defibrillators technology: up-front cost or daily cost? Int J Technol Assess Health Care. 2011;27(3):201-206.

35. Shafat T, Baumfeld Y, Novack V, Konstantino Y, Amit G. Significant differences in the expected versus observed longevity of implantable cardioverter defibrillators (ICDs). Clin Res Cardiol. 2013;102(1):43-49. 


\section{Supplementary material}

The probability of first replacement in year $n$ (i.e., $P_{n}$ with $n$ ranging from 1 to 6 years) was calculated as an incremental difference in battery failure rates (i.e., $\left.F_{n}-F_{(\mathrm{n}-1)}\right)$. The probabilities of second replacement in year $n\left(Q_{n}\right.$ with $n$ ranging from 1 to 6 years) and third replacement in year $n\left(R_{n}\right.$ with $n$ ranging from 1 to 6 years) were calculated by the formulae $Q_{n}=\sum_{x=1}^{n} p_{x} * p_{(n-x)}$ and $R_{n}=\sum_{x=1}^{n} Q_{x} * p_{(n-x)}$, respectively.

\section{Publish your work in this journal}

ClinicoEconomics and Outcomes Research is an international, peerreviewed open-access journal focusing on health technology assessment, pharmacoeconomics and outcomes research in the areas of diagnosis, medical devices, and clinical, surgical and pharmacological intervention. The economic impact of health policy and health systems organization also constitute important areas of coverage. The manuscript management system is completely online and includes a very quick and fair peer-review system, which is all easy to use. Visit http://www.dovepress.com/testimonials.php to read real quotes from published authors. 